\title{
Surgical Technique of Late Spontaneous IOL-Capsular Bag Complex Dislocation with Low Corneal Endothelial Cell Density: A Case Report
}

\author{
Firman Setya Wardhana ${ }^{1,2}$, Dhimas Hari Sakti ${ }^{1,2}$, Supanji ${ }^{1,2}$, Muhammad Bayu Sasongko ${ }^{1,2}$, Tri Wahyu \\ Widayanti ${ }^{1,2}$, Angela Nurini Agni ${ }^{1,2}$ \\ ${ }^{1}$ Department of Ophthalmology; Faculty of Medicine, Public Health and Nursing; Universitas Gadjah Mada/ Dr. Sardjito \\ General Hospital, Yogyakarta, Indonesia \\ ${ }^{2}$ Dr. Yap Eye Hospital, Yogyakarta, Indonesia
}

\section{ABSTRACT}

Introduction: IOL-capsular bag complex dislocation is a rare but serious complication of phacoemulsification surgery. Technique to repair this complication should be based on various clinical parameters including quality of corneal endothelial cells and the type of dislocated IOL.

Method: We present a case of a 67-year-old male with left eye spontaneous one-piece foldable IOL-capsular bag complex dislocation to vitreous cavity 4 years after phacoemulsification surgery. Visual acuity of the left eye was 1/60, pupil was round with $3 \mathrm{~mm}$ diameter and IOP was $15 \mathrm{mmHg}$. Noncontact specular microscopy examination showed that the corneal endothelial cell density was $1100 \mathrm{cells} / \mathrm{mm}^{2}$. It was managed with 23-gauge posterior vitrectomy, IOL evacuation to anterior chamber, releasing the capsular bag and repositioning the $1 O L$ into posterior chamber by sutured scleral fixation.

Result: Follow-up at $6^{\text {th }}$ month, best corrected visual acuity of the left eye achieved 6/6, $10 \mathrm{~L}$ at central position and the last corneal endothelial cell density was $1076 \mathrm{cell} / \mathrm{s} / \mathrm{mm}^{2}$.

Conclusions: Late spontaneous IOL-capsular bag complex dislocation with low corneal endothelial cell density can be safely managed with proper surgical technique. Vitrectomy and sutured scleral fixation of the previously dislocated $\mathrm{IOL}$ were effective in managing such case. Longer follow-up should be done to assure the stability of $I O L$ position and the quality of corneal endothelial cells.

Key words: IOL-capsular bag complex, dislocation, vitrectomy, corneal endothelial cell, scleral fixation Cite This Article: WARDHANA, Firman Setya et al. Management of Late Spontaneous IOL-Capsular Bag Complex Dislocation with Low Corneal Endothelial Cell Density: A Case Report. International Journal of Retina, [S.I.], v. 2, n. 1, feb. 2019. ISSN 2614-8536. Available at: <https://www.ijretina.com/index.php/ijretina/article/view/54>

\begin{tabular}{l} 
*Correspondence to: \\
Firman Setya Wardhana, \\
Department of Ophthalmology, \\
Universitas Gadjahmada, \\
firman.sw@gmail.com \\
\hline
\end{tabular}

*Correspondence to:

Firman Setya Wardhana, Universitas Gadjahmada

firman.sw@gmail.com

\section{INTRODUCTION}

Intraocular lens (IOL)-capsular bag complex dislocation is uncommon but considered as serious complication following phacoemulsification. Based on the time of onset, IOL dislocation is divided into early and late case. IOL dislocation occurring 3 months or later following cataract surgery is defined as late spontaneous IOL dislocation ${ }^{1}$. The incidence of surgery for late $\mathrm{IOL}$ dislocation is $0,032-0,28 \%$ from all cataract surgery ${ }^{2,} 3$. Possible predisposing factors late IOLcapsular bag complex dislocation were to be pseudoexfoliation, retinitis pigmentosa, postvitrectomy, trauma, long axial length and age ${ }^{4}$. Progressive zonular insufficiency and capsular bag contraction after many year of uncomplicated cataract surgery can result of in the bag IOL dislocation ${ }^{1,4}$. In insufficiency of capsular support, the management of late
IOL-capsular bag dislocation is varied. In principle, there are 2 types of surgical approaches: repositioning of the existing $\mathrm{IOL}$ by fixating it to the scleral wall or to the iris or exchange the IOL-capsular bag complex with new IOL. In case of totally dislocated IOLcapsular bag complex to vitreous cavity, it requires pars plana vitrectomy before repositioning or exchanging the $\mathrm{IOL}^{5}$.

At present there is no consensus which technique the best for management of late IOL-capsular bag complex dislocation and several surgical procedures have good result ${ }^{5-7}$. We report a case of totally dislocated IOL capsular bag complex to vitreous cavity with low endothelial cell density (ECD) and describe its management with vitrectomy and fixating the previous $\mathrm{IOL}$ to posterior chamber. 


\section{CASE PRESENTATION}

A 67-year-old man presented to Yap Eye Hospital Yogyakarta, complaining of gradually blur vision on the left eye without pain for 1 month. He had hypertension but no other systemic diseases or eye trauma before. He underwent phacoemulsification surgery on the left eye at other city 4 years ago.

On initial evaluation, visual acuity of the left eye at presentation was $1 / 60$ with best-corrected visual acuity (BCVA) 6/12, iris was normal with round pupil, no relative afferent pupillary defect (RAPD) and IOP was $15 \mathrm{mmHg}$. On fundoscopy examination, retina, macula and optic nerve head $(\mathrm{ONH})$ were within normal limit but there was mild vitreous opacity. IOL-capsular bag complex was looked totally dislocated to posterior chamber. Noncontact specular microscopy (Topcon, SP 3000P) examination showed that the ECD was low as 1100 cells $/ \mathrm{mm}^{2}$.

We managed the patient with 23-gauge pars plana posterior vitrectomy under general anaesthesia. Firstly, vitrectomy was done to the anterior vitreous around pupil than continuous to the deeper and peripheral vitreous. Corneal incision was made with keratome at 12 o'clock and 2 o'clock as the way for forceps to hold the IOL during manoeuvre. Besides, the incision on 12 o'clock was made for externalizing the suture and haptics on the next steps. IOL capsular bag complex was evacuated from the surface of retina to anterior chamber with endoforceps. It was a foldable acrylic one-piece IOL with closed loop haptics covered with fibrotic capsular bag. Capsular bag than was released from the $\mathrm{IOL}$ with the endoforceps so the $\mathrm{IOL}$ can be placed above the iris. Two sites of conjunctiva were incised and $3 \times 1 \mathrm{~mm}$ limbal based scleral pockets were made with crescent knife $3 \mathrm{~mm}$ from the limbus at 1 and 7 o'clock. A 10.0 double-armed polypropylene, monofilament $\left(\right.$ Aclon $\left.^{\circledR}\right)$ suture was introduced inside the pocket through the scleral wall at $2 \mathrm{~mm}$ from the limbus. Thereafter, a 26-gauge cannula needle was introduced from the opposite scleral pocket through the scleral wall to catch the needle, followed by retraction of the needlecannula complex from the scleral pocket incision port. This procedure was repeated so there was four-point suture fixation. The sutures were pulled and externalized through the 12 o'clock corneal incision and cut in the middle, so there were two side of sutures, consist of two sutures for each side, right-side sutures from the 7 o'clock and leftside sutures from 1 o'clock

First haptic was externalized through corneal incision and tied with the right-side sutures. The IOL than rotated and second haptic was externalized through corneal incision and tied with the left side sutures. IOL than be repositioned behind the iris and adjusted so the IOL was centrally placed. Scleral sutures on the both side were tied and the knot was lied inside the scleral pockets. Corneal incision was sutured with 10.0 nylon. All the scleral canula was pulled and trans-conjunctival sclerotomy suture was applied with 7.0 Vicryl. The last, all conjunctival incision was sutured with 8.0 Vicryl. Summary of the surgery is shown in the figure 1.

At follow up, no complications were noted, the knots were well buried inside the sclera pockets. Follow-up at 6 th month, best corrected visual acuity of the left eye could achieve 6/6, IOL still at central position and the last corneal endothelial cell density was slightly reduced to 1076 cells $/ \mathrm{mm}^{2}$ (Fig. 2).

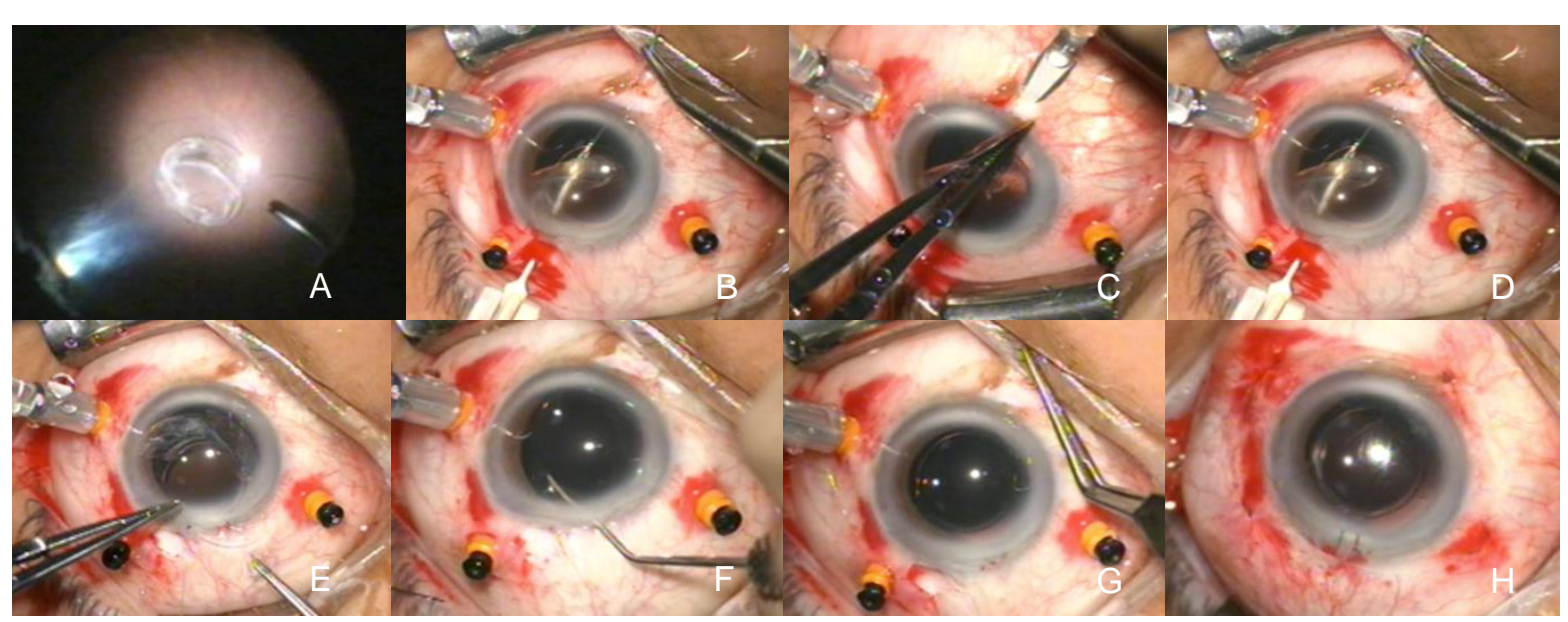

Figure 1. Summary of surgery. (A) IOL-capsular bag complex was shown during posterior pars plana vitrectomy. (B) IOL was elevated and then released the capsular bag with endoforceps. (C) Scleral pocket was made after incised the conjunctiva. (D) 10.0 polypropylene monofilament suture was inserted through the scleral pocket. (E) Externalized haptic was tied. (F) IOL was repositioned to posterior chamber with lens rotator instrument. (G) Suture was adjusted so the IOL was centrally placed.(H) End of surgery with all sclerotomies, conjunctiva, and corneal incision were sutured. 


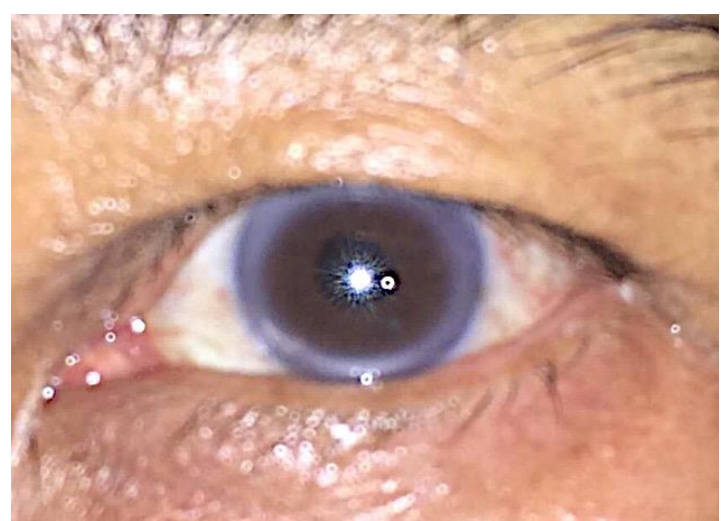

Figure 2. Follow up time at $6^{\text {th }}$ month.

\section{DISCUSSION}

IOL-capsular bag dislocation is recognized a late complication even after uneventful cataract surgery ${ }^{8}$. In a recent observational study, it was shown that the cumulative risk of $\mathrm{IOL}$ dislocation at 5, 10, 15, 20, 25 years after cataract extraction was $0,1 \%, 0,1 \%, 0.2 \%, 0.7 \%$ and $1.7 \%$ respectively ${ }^{9}$. Possible presdispossing factors were found to be pseudoexfoliation, retinitis pigmentosa, postvitrectomy, trauma, uveitis, a long axial length and age ${ }^{4}$. According to Fernandez-Buenaga et al, mean age surgery due to IOL dislocation was 71.2 years (range 41-97). Most of patient who underwent explantation due to late IOL dislocation were male $(68,9 \%)^{6}$. In this case we present a 67-year-old man, but we did not find any abnormality on the eye such pseudoexfoliation, post vitrectomy, retinitis pigmentosa, uveitis or long axial length that could be presdispossing factor. There were also no trauma event or hardly rubbing habit on the eye. By analysed the IOLcapsular bag complex appearance during pars plana vitrectomy (PPV), we suggest the mechanism causing late IOL-bag complex dislocation is related to extreme capsular shrinkage, it is called "capsular contraction syndrome". The rate of late "in-the-bag" IOL dislocation has increased since continuous curvilinear capsulorrhexis (CCC) became popular among surgeon. Although the advent of CCC made secure in-the-bag IOL fixation, sphincter effect of fibrosis around an intact CCC appears to be a factor in development of significant capsular shrinkage. With progressive weakening of zonules make them vulnerable to continuous centripetal forces due to capsular shrinkage and cause zonules rupture ${ }^{4}$.

In case of totally posterior dislocated IOL-capsular bag complex, pars plana vitrectomy (PPV) surgery is needed to evacuate the IOL. The dislocated IOL may be grasped with intraocular forceps and brought into the anterior chamber (AC) or use perfluorocarbon (PFC) liquid to floating the IOL and then safely grasping it with intraocular forceps ${ }^{10}$.
Following PPV, patients have numerous available option for secondary visual rehabilitation from the aphakia. In absent or insufficient of capsular support, IOL may be sutured to the sclera (transscleral suture fixation) or iris, exchanged for an AC IOL or using aphakic spectacle or contact lens correction ${ }^{5,10}$.

In this case, PPV was done to release vitreous traction and evacuate the IOL. Capsular bag was released from the IOL with forceps and the IOL was placed to AC. Both haptics was tied outside the eye after temporary externalized through the small $(3 \mathrm{~mm})$ corneal incision and then repositioning the IOL to posterior chamber. Considering the low ECD in this patient $\left(1100 \mathrm{cell} / \mathrm{mm}^{2}\right)$, refixation the previous $\mathrm{IOL}$ is without exchange the $\mathrm{IOL}$ is preferred to minimize manipulation of the eye. In $\mathrm{IOL}$ exchange technique, extraction the IOL could made more damage to the eye structure and induced corneal astigmatism by large wound for extracting the IOL.

Most common postoperative complication of the refixation or exchange $\mathrm{IOL}$ is decrease of ECD. AC IOL implantation for low ECD patient is avoided because potential complication related to $\mathrm{AC} \mathrm{IOL} \mathrm{may} \mathrm{be} \mathrm{a} \mathrm{gradual}$ decrease of $E C D^{10}$. Kristianlund et al in their study found postoperative significant ECD loss of $10 \%$ in IOL exchange group than nonsignificant 3\% ECD loss in repositioning group at $6^{\text {th }}$ month follow-up ${ }^{5}$. In this case, postoperative ECD loss about $2.18 \%$ at 6 -month follow-up. Refixation IOL of posterior chamber $\mathrm{IOL}$ is safe but need longer surgical time that indicate more complexity of the procedure than exchange the IOL with iris clip or open loop $A C \mathrm{IOL}^{5,11}$.

During the follow-up time, other potential complication of scleral fixation technique are hypotony or sclerotomy leakage, vitreous hemorrhage, cystoid macular edema, retinal break, retinal detachment or suture related complication such as knot exposure, suture degeneration or breakage and IOL decentration ${ }^{11}$. Until $6^{\text {th }}$ month followup time we did not find any of those complications on this patient.

\section{CONCLUSION}

Late spontaneous IOL-capsular bag complex dislocation to posterior is uncommon but serious complication even after uncomplicated phacoemulsification surgery. Deciding the best technique for management this complication must be consider to individual clinical setting. Repair of IOL-capsular bag complex dislocation with low corneal endothelial cell density with vitrectomy and sutured scleral fixation of the previously dislocated IOL was safe and effective. Longer follow-up should be done to assure the stability of IOL position and the quality of corneal endothelial cells. 


\section{REFERENCES}

1. Davis D, Brubaker J, Espandar L, Stringham J, Crandall A, Werner $L$, et al. Late in-the-bag spontaneous intraocular lens dislocation: evaluation of 86 consecutive cases. Ophthalmology. 2009;116(4):664-70.

2. Jakobsson $G$, Zetterberg M, Lundstrom M, Stenevi U, Grenmark R, Sundelin K. Late dislocation of in-the-bag and out-of-the bag intraocular lenses: ocular and surgical characteristics and time to lens repositioning. J Cataract Refract Surg. 2010;36(10):1637-44.

3. Clark A, Morlet N, Ng JQ, Preen DB, Semmens JB. Whole population trends in complications of cataract surgery over 22 years in Western Australia. Ophthalmology. 2011;118(6):1055-61.

4. Ascaso FJ, Huerva V, Grzybowski A. Epidemiology, Etiology, and Prevention of Late IOL-Capsular Bag Complex Dislocation: Review of the Literature. J Ophthalmol. 2015;2015:805706.

5. Kristianslund $\mathrm{O}$, Raen $\mathrm{M}$, Ostern $\mathrm{AE}$, Drolsum $\mathrm{L}$. Late In-the-Bag Intraocular Lens Dislocation: A Randomized Clinical Trial Comparing Lens Repositioning and Lens Exchange. Ophthalmology. 2017;124(2):151-9.

6. Fernandez-Buenaga $\mathrm{R}$, Alio $\mathrm{JL}$, Perez-Ardoy $\mathrm{AL}$, Larrosa-Quesada A, Pinilla-Cortes L, Barraquer R, et al. Late in-the-bag intraocular lens dislocation requiring explantation: risk factors and outcomes. Eye (Lond). 2013;27(7):795-801; quiz 2.

7. Eum SJ, Kim MJ, Kim HK. A Comparison of Clinical Outcomes of Dislocated Intraocular Lens Fixation between In Situ Refixation and Conventional Exchange Technique
Combined with Vitrectomy. J Ophthalmol. 2016;2016:5942687.

8. Shah MA, Shah SM, Mehta R, Shah P. Spontaneous dislocation of lens bag with acrylic lens after uneventful cataract surgery - unusual complication of cataract surgery. GMS Ophthalmology Cases. 2015;5.

9. Pueringer SL, Hodge DO, Erie JC. Risk of Late Intraocular Lens Dislocation After Cataract Surgery, 19802009: A Population-Based Study. American Journal of Ophthalmology. 2011;152(4):618-23.

10. Yang CS, Chao YJ. Long-term outcome of combined vitrectomy and transscleral suture fixation of posterior chamber intraocular lenses in the management of posteriorly dislocated lenses. J Chin Med Assoc. 2016;79(8):450-5.

11. Jing W, Guanlu L, Qianyin Z, Shuyi L, Fengying $H$, Jian $L$, et al. Iris-Claw Intraocular Lens and Scleral-Fixated Posterior Chamber Intraocular Lens Implantations in Correcting Aphakia: A Meta-Analysis. Invest Ophthalmol Vis Sci. 2017;58:3530-6.

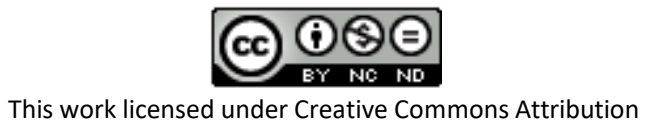

